\title{
Genome-wide association analysis reveals genetic loci and candidate genes associated with intramuscular fat in Duroc pigs
}

\author{
Xingwang WANG ${ }^{1}$, Rongrong DING ${ }^{\mathbf{1}}$, Jianping QUAN ${ }^{\mathbf{1}}$, Linxue YANG ${ }^{\mathbf{1}}$, Ming YANG ${ }^{\mathbf{2}}$, Enqin ZHENG ${ }^{\mathbf{1}}$, \\ Dewu LIU ${ }^{1}$, Gengyuan CAI ${ }^{1,2}$, Zhenfang WU $(\bowtie)^{1,2}$, Jie YANG $(\bowtie)^{1}$ \\ 1 College of Animal Science and National Engineering Research Center for Breeding Swine Industry, South China Agricultural University, \\ Guangzhou 510642, China \\ 2 National Engineering Research Center for Breeding Swine Industry, Guangdong Wens Foodstuffs Group Co., Ltd., Yunfu 527400, China
}

\begin{abstract}
Intramuscular fat (IMF) is a major meat-quality trait in pigs. The content of IMF is directly associated with the taste and flavor of pork. As a complex trait, there could be multiple genes affecting IMF content in pork. Genomewide association study is a powerful tool to detect genomic regions associated with phenotypic variations. The objectives of the present study were to identify or refine the positions of genomic regions affecting IMF, and to characterize candidate genes and pathways that may influence this trait. Of note, we identified a significant region in longissium dorsi muscle in a Duroc pig population for IMF content with PorcineSNP60 v2 BeadChip. This region spans $1.24 \mathrm{Mb}$ on chromosome 8 and had been identified as a quantitative trait locus for IMF in Pietrain, Large White, Landrace, and Leicoma pigs. In this region, eight SNPs were significantly associated with IMF content. Three genes proximal to these significant SNPs were considered candidate genes, including ZDHHC16, LOC102162218 and PCDH7. Our results confirm several previous findings and highlight several genes that may contribute to IMF variation in Duroc pigs.
\end{abstract}

Keywords Duroc pigs, genome-wide association analysis, intramuscular fat

\section{Introduction}

With the advances in high-throughput genotyping platforms, much effort has been spent on identifying molecular markers and genes related to complex traits using genomewide association studies (GWAS) in several species. Such information helps in the development of marker assisted

Received December 31, 2016; accepted March 6, 2017

Correspondences: wzfeamil@163.com, jieyang2012@hotmail.com breeding as well as improving understanding of the molecular mechanisms underlying the target traits.

One of the main sources of human-consumed meat is pork, which represents more than $40 \%$ of the meat produced worldwide. The success of pig production is strongly related to improvements in growth and carcass yield. Meat-quality traits are essential for the processing industry and consumer acceptance ${ }^{[1]}$, as a result, these qualitative traits have been the subject of numerous studies in breeding programs. Also, consumer preference for high quality meat has required the identification of new breeding objectives, such as high intramuscular fat (IMF). Skeletal muscle is composed of muscle fiber, fat, connective tissue, blood vessel and nerve tissue. Fat is an essential component. Muscle fat is usually divided into intermuscular fat and IMF. IMF, referred also as marbling, consists of the fat scattered inside a muscle. As an important meat quality trait, IMF content has been extensively studied because of its effect on sensory, flavor, juiciness, tenderness and nutritional quality of meat. In addition, a muscle with an adequate content of IMF is particularly suitable for transformation for dry-cured products $^{[2]}$. IMF heritability value is estimated to average 0.50 , indicating a genetic basis for this trait in pigs ${ }^{[3,4]}$. However, it is difficult to elucidate the genetic basis of IMF as several biochemical and metabolic processes influence fat deposition in muscles and these processes are determined by a set of interrelated genes and their interaction with environmental factors, including nutrition $^{[5,6]}$. It has been shown that IMF content varies considerably in diverse breeds. For example, Chinese indigenous breeds have higher IMF contents than the commercial breeds, with the Duroc breed having the highest ${ }^{[7,8]}$.

To date, multiple quantitative trait loci (QTLs) associated with IMF have been detected on pig chromosomes 
$1,2,5,6,8,12,13$ and $17^{[3]}$ and deposited in the pig QTLdb (http://www.animalgenome.org/cgi-bin/QTLdb/ SS/index). A combined linkage scan and GWAS revealed significant pleiotropic regions with effects on both IMF and back-fat tissues ${ }^{[9]}$. In particular, a QTL on SSC6 harboring the heart fatty-acid binding protein $(H-F A B P)$ gene explained $15 \%$ to $20 \%$ of phenotypic variation in IMF content in different crosses ${ }^{[10-12]}$. In addition to QTLs, several genes have been characterized for this trait, such as leptin receptor $(L E P R)^{[8]}$, melanocortin 4 receptor $(M C 4 R)^{[8]}$ and insulin growth factor $2(I G F 2)^{[13]}$. Thanks to the high-throughput genotyping PorcineSNP60 BeadChip (Illumina, San Diego, CA, USA), it is feasible to conduct genome-wide association studies (GWAS) for IMF content and fluorescent markers associated with intramuscular fat content.

In the present study, a Duroc pig population, the main breed utilized for terminal sire, was genotyped with PorcineSNP60 v2 BeadChip to identify markers and genes associated with IMF contents.

\section{Materials and methods}

\subsection{Animals}

All experimental procedures met the guidelines of the Animal Care and Use Committee, South China Agricultural University, Guangzhou, China (Approval number SCAU\#0017) and every effort was taken to minimize animal suffering. Animal and analysis workflow samples from 359 Duroc boars born between 2011 and 2014 were collected from Guangdong Wens Foodstuffs Group Co., Ltd., Yunfu, China.

\subsection{Phenotyping and estimated breeding values}

Pigs were scanned with an Aloka 500V SSD ultrasound machine (Corometrics Medical Systems, USA) to measure their IMF content in longissimus dorsi muscle. The images were collected at 6 to $7 \mathrm{~cm}$ off the midline across the tenth to the eleventh ribs, and these images were used to predict IMF content with the BioSoft Toolbox for Swine software (http://www.biotronics-inc.com/Lesson\%20Series\% 20One\%20-\%20Marbling.pdf).

\subsection{Genotyping and quality control}

Duroc pig genomic DNA was extracted by standard protocols from ear tissue samples, and DNA quality was assessed by ratios of light absorption $\left(\mathrm{A}_{260 / 280}\right.$ and $\left.\mathrm{A}_{260 / 230}\right)$ and electrophoresis. DNA concentration was adjusted to $50 \mathrm{ng} \cdot \mu \mathrm{L}^{-1}$. All animals were genotyped with the PorcineSNP60 v2 BeadChip which contains 61565 SNP markers across the entire genome ${ }^{[14]}$. Quality control was performed using PLINK as previously described ${ }^{[15]}$. Briefly, animals with call rates of $>0.99$ and SNP with call rates of $>0.99$, minor allele frequency $>0.01, P$ value $>$ $10^{-6}$ for the Hardy-Weinberg equilibrium (HWE) test were included. After this filtering procedure, a final set of 41793 informative SNPs from 359 pigs was used in subsequent analyses.

\subsection{Genome-wide association study}

A GWAS was conducted using a linear mixed model implemented in $\mathrm{R}$ package GenABEL ${ }^{[16,17]}$. The model included a random polygenic effect for which the variancecovariance matrix is proportional to genome-wide IBS and includes year and season as fixed effects. The model is $\boldsymbol{Y}=$ $\mu+\boldsymbol{X} b+K w+\boldsymbol{S} c+\boldsymbol{Z} a+e$, where $\boldsymbol{Y}$ is the vector of IMF contents of all genotyped pigs, $\mu$ is the overall mean, $b$ is the vector of fixed effects including year and season, $K$ is the regression coefficient of individuals IMF contents, and $e$ is the vector of residual errors with $\mathrm{e} \sim \mathrm{N}\left(0, \boldsymbol{I} \sigma_{\mathrm{e}}{ }^{2}\right)$ (with $\boldsymbol{I}$ the identity matrix and $\sigma_{\mathrm{e}}^{2}$ the residual variance), $w$ is the vector of bodyweight of individuals considered as covariance, $c$ is the vector of SNP effects, $a$ is the vector of random polygenic additive effects calculated as $\mathrm{N}(0$, $\boldsymbol{G}{\sigma_{\mathrm{a}}}^{2}$ ) (with $\boldsymbol{G}$ the genomic kinship matrix calculated from the pedigree and $\sigma_{\mathrm{a}}^{2}$ is the polygenic additive variance), and $\boldsymbol{X}, \boldsymbol{S}$, and $\boldsymbol{Z}$ are the relative incidence matrix for $b, c$, and $a$, respectively.

The Bonferroni method was used to determine the genome-wide significance threshold, in which the conventional $P$-value was divided by the number of tests performed ${ }^{[18]}$. According to the Bonferroni method, the genome-wide significant (significant) and chromosomewide significant (suggestive) thresholds were $P<0.05 / \mathrm{N}$ and $P<1 / \mathrm{N}$, respectively, where $\mathrm{N}$ is the number of SNPs tested in the analyses. In the present study, the significant and suggestive thresholds were $1.20 \times 10^{-6}(0.05 / 41793)$ and $2.39 \times 10^{-5}(1 / 41793)$, respectively.

\subsection{Quantile-quantile plot}

Given that population stratification greatly impacts GWAS reliability, quantile-quantile (Q-Q) plot analysis is considered an effective way to determine the reliability of the GWAS results. In a Q-Q plot, the horizontal axis represents the expected $-\log _{10}(P$ value $)$, and the vertical axis represents the observed $-\log _{10}(P$ value $)$. The diagonal line represents $y=x$. The shaded region shows a 95\% confidence interval based on a beta distribution. An overall deviation above the diagonal identity line is generally suggestive of severe population stratification ${ }^{[19]}$. Deviations from the diagonal line suggest that either the assumed distribution is incorrect or that the sample contains values arising in some other manner, as by a true association ${ }^{[20]}$. The Q-Q plot was constructed using the R software. 


\subsection{Characterization of candidate genes}

SNP positions from the most recent Sus scrofa genome (version 10.2) were downloaded from https://www.animalgenome.org/pig. The NCBI annotation version of S. scrofa genome was used to find the genes which were nearest the significant SNPs (https://www.ncbi.nlm.nih.gov/genome/? term $=$ pig). To seek further gene function information, human homologs of these genes were queried in the Ensemble BioMart (http://www.ensembl.org/biomart/ martview). To assign significant SNPs positions to previously mapped QTLs in pigs, all pig QTL data was downloaded from http://www.animalgenome.org/cgi-bin/ QTLdb/SS/download?file $=$ gbpSS_10.2 (accessed 3 April $2016)^{[21]}$.

\section{Results}

\subsection{Phenotypes and quality control of genotypes}

Prior to GWAS analysis, the distribution of all phenotypes was assessed using the Shapiro test ${ }^{[22]}$. All phenotypic data conformed to the Gaussian distribution. In total, 18792 markers were excluded as having a low $(<1 \%)$ minor allele frequency, 489 markers were excluded because of low $(<99 \%)$ call rate and 840 markers were excluded because they were not in HWE $\left(P<10^{-6}\right)$. A final set of 41973 SNPs was kept for subsequent GWAS analysis of 359 pigs. The number of markers on each chromosome and average distances between two markers after quality control are given in the supplementary materials (Table S1). The average physical distance between two neighboring SNPs on the same chromosome was approximately $73.3 \mathrm{~kb}$, ranging from 54.7 (SSC14) to $191.4 \mathrm{~kb}$ (SSC X).

\subsection{Assessment of population stratification}

The Q-Q plot of test statistics in GWAS is shown in Fig. 1a. No overall systematic bias is observed, and the deflation factor $\lambda$ was 1.03 , indicating that population stratification had been eliminated.

\subsection{Significant SNPs and candidate genes}

The Manhattan plot of GWAS for IMF after genomic control in the tested Duroc pigs is illustrated in Fig. 1b. The allelic effect of the most significant SNP on IMF content in pork is shown in the Fig. 1c. The significantly associated SNPs for this trait are listed in Table 1. Eight significant SNPs were identified. Chromosomes and exact positions based on the S. scrofa genome as well as the genes nearest to significant SNPs are listed in Table 1. Five of eight these SNPs were found in the intergenic regions. The remaining three SNPs were in introns of the protocadherin-7 $(\mathrm{PCDH7})$ gene. Three genes including zinc finger DHHC-type containing 16 (ZDHHC16) pseudogene, $L O C 102162218$ and $P C D H 7$ were proximal to significant SNPs (Fig. 1d).

\subsection{Comparison with previously mapped QTLs in pigs}

All eight significant SNPs identified in this study span an interval of $1.24 \mathrm{Mb}$ and fall in previously identified QTLs for IMF in Pietrain, Large White, Landrace, and Leicoma pigs (Table $\mathrm{S} 2)^{[23]}$.

\section{Discussion}

The study presented here is a GWAS for IMF content in Duroc pigs. We identified eight novel SNPs that have not been detected in previous studies. Notably, all eight SNPs are located within a $1.24 \mathrm{Mb}$ region containing three candidate genes.

ZDHHC16 is a protein coding gene in the DHHC domain family. The DHHC domain is a protein domain that acts as an enzyme, which adds a palmitoyl chemical group to proteins in order to anchor them to cell membranes ${ }^{[24]}$. Recent studies indicated that palmitoylation controls lipid metabolism. DHHC17 modulates ClipR59 plasma membrane binding to regulate $A k t$ signaling and glucose transporter (Glut4) membrane translocation in adipocytes ${ }^{[25]}$. Recent profiling of adipocytes, major fat storage cells, identified a wide variety of palmitoylated proteins including different transporters and components of lipid and glucose metabolism pathways ${ }^{[26]}$. One such example is the leptin signaling pathway. Leptin, a peptide hormone produced in adipocytes, regulates metabolism by suppressing feeding and increasing energy consumption. An increase in protein palmitoylation was observed in pancreatic $\beta$-cells upon glucose stimulation ${ }^{[27]}$. Also, a lack of palmitoylation impaired leptin signaling and increased levels of insulin in the serum ${ }^{[28]}$. In addition, proper expression of $\mathrm{DHHC17}$ can prevent triggering apoptosis of pancreatic $\beta$-cell by interleukin $1 \beta$ during inflammation ${ }^{[29]}$. Consequently, palmitoylation can impact fat synthesis by regulating the level of leptin and insulin. Another palmitoyltransferase, amyloid precursor protein (App), is one of 20 Drosophila DHHC palmitoyltransferases, transmembrane proteins that add palmitates to cytoplasmic proteins, in order to anchor them to cell membranes. It regulates protocadherin fat signaling in growth by controlling the normal subcellular localization and activity of Dachs ${ }^{[30]}$. Pseudogenes populate the mammalian genome as remnants of artifactual incorporation of coding mRNAs into transposon pathways ${ }^{[31]}$. Pseudogenes can regulate paralogous genes expression by means of the RNA interference and piRNA pathway ${ }^{[32-34]}$. Therefore, ZDHHC16 pseudogene could control lipid metabolism and fat deposition by regulating related genes 

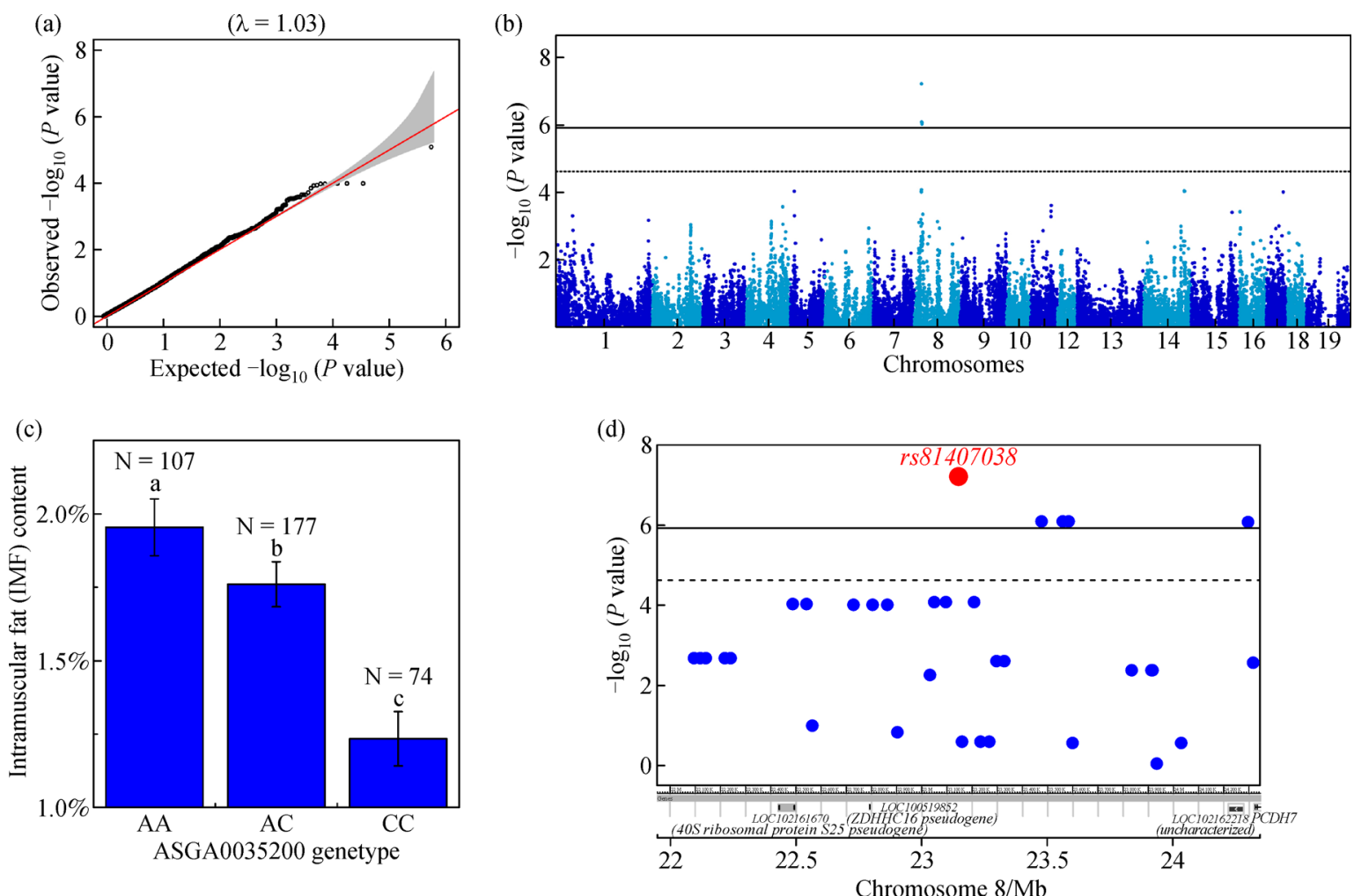

Fig. 1 (a) Quantile-quantile (Q-Q) plot in the left panel shows the observed versus expected - $\log _{10}(P$-value); (b) Manhattan plot of genome-wide association studies for IMF in male Duroc pigs. $-\log _{10}(P$-value $)$ of the quantified SNPs were plotted against their genomic positions. Different colors indicate different chromosomes. The solid and dashed lines indicate the 5\% genome-wide and chromosomewide Bonferroni-corrected thresholds, respectively. Chromosome 19 stands for the X chromosome; (c) bar plot showing allelic effect of the most significant SNP on IMF content in pork; (d) in the region plot, $-\log _{10}(P$-value) of the quantified SNPs were plotted against their genomic positions. The solid and dashed lines indicate the 5\% genome-wide and chromosome-wide Bonferroni-corrected thresholds, respectively. The red dot is the most significant SNP. The nearest genes are shown at the bottom of the figure.

Table 1 Significant SNPs and their nearest genes for $\mathrm{IMF}^{1}$ content

\begin{tabular}{|c|c|c|c|c|c|c|c|c|}
\hline Trait $^{1}$ & SNP ID & $\mathrm{SSC}^{2}$ & Location $^{3} / \mathrm{bp}$ & $\begin{array}{l}\text { Adjusted } P \\
\text { value }\end{array}$ & Nearest gene & Gene location $^{4}$ & Distance $^{5} / \mathrm{bp}$ & $\begin{array}{c}\text { Homo sapiens } \\
\text { homologs }\end{array}$ \\
\hline \multirow{8}{*}{ IMF } & ASGA0038200 & 8 & 23147683 & $6.08 \times 10^{-8}$ & ZDHHC16 pseudogene & $8: 22,792,997 . .22,794,126$ & 353557 & ZDHHC16 \\
\hline & H3GA0024419 & 8 & 23477511 & $8.12 \times 10^{-7}$ & ZDHHC16 pseudogene & 8: $22,792,997 . .22,794,126$ & 683385 & ZDHHC16 \\
\hline & DRGA0008413 & 8 & 23561975 & $8.12 \times 10^{-7}$ & LOC102162218 & 8: $24,220,615 . .24,276,003$ & -658640 & $\mathrm{NA}^{6}$ \\
\hline & ASGA0038214 & 8 & 23585035 & $8.12 \times 10^{-7}$ & LOC102162218 & $8: 24,220,615 . .24,276,003$ & -635580 & NA \\
\hline & ASGA0089289 & 8 & 24298660 & $8.42 \times 10^{-7}$ & LOC102162218 & $8: 24,220,615 . .24,276,003$ & 22657 & NA \\
\hline & DRGA0008418 & 8 & 24386346 & $8.42 \times 10^{-7}$ & $\mathrm{PCDH7}$ & 8: $24,323,016 . .24,732,096$ & intron & $\mathrm{PCDH} 7$ \\
\hline & DRGA0008423 & 8 & 24646964 & $8.42 \times 10^{-7}$ & $\mathrm{PCDH} 7$ & 8: $24,323,016 . .24,732,096$ & intron & $\mathrm{PCDH7}$ \\
\hline & MARC0038273 & 8 & 24568164 & $9.36 \times 10^{-7}$ & PCDH7 & 8: $24,323,016 . .24,732,096$ & intron & PCDH7 \\
\hline
\end{tabular}

Note: ${ }^{1}$ IMF, intramuscular fat; ${ }^{2}$ Sus scrofa chromosome; ${ }^{3}$ SNP positions in Ensembl; ${ }^{4}$ Gene location in Ensembl; ${ }^{5}$ The SNP located in the upstream/downstream of the nearest gene; ${ }^{6} \mathrm{NA}$, not available.

and is a functionally plausible candidate gene for IMF content in pork.

LOC102162218 is a recently predicted and poorly characterized gene, and no homologous gene has been observed in the human or mouse.

The $P C D H 7$ gene belongs to the protocadherin gene family, a subfamily of the cadherin superfamily. It encodes a protein with an extracellular domain containing 7 cadherin repeats, and is thought to function in cell-cell recognition and adhesion. Alternative splicing yields isoforms with unique cytoplasmic tails ${ }^{[35]}$. Protocadherin genes directly affect meat-quality traits. protocadherin 19 $(P C D H 19)$ is related to the ultimate $\mathrm{pH}$ of chicken meat ${ }^{[36]}$. Moreover, $P C D H 19$ is significantly associated 
with estimated breeding values for residual feed intake in cattle. Also, the degree of methylation of the protocadherin 15 (PCDH15) precursor promoter was associated with muscle fiber density and drip loss in male three-yellow chickens $^{[37]}$. Protocadherin genes also affect fat content. According to the International Mouse Phenotype Consortium, protocadherin 18 (PCDH18) knockout mice have a decreased total body fat phenotype, indicating that PCDH18 is associated with fat deposition. Unfortunately, there is no $P C D H 7$ knockout mouse at present. In pigs, a $P C D H 7$ homolog expressed differently in distinct adipocytes, suggesting that the expression level of $\mathrm{PCDH7}$ may affect formation of different lipids ${ }^{[38]}$. The significant enrichment of rare variants in the protocadherin genes has been observed in a group of extremely obese individuals but not in the general population, indicating an association between rare variants in the protocadherin cluster genes and extreme obesity ${ }^{[39]}$. Protocadherin genes may also influence IMF by affecting eating. Knocking out the protocadherin gamma subcluster leads to a change in eating behavior in mice ${ }^{[40]}$. This suggests that rare variants in the $P C D H$-genes may also have an impact on food intake in pigs and $\mathrm{PCDH} 7$ in particular is an interesting candidate gene for IMF content in pork.

\section{Conclusions}

In summary, we identified a new genomic region and three genes associated with IMF content in porcine genome. Both $Z D H H C 16$ pseudogene and $P C D H 7$ had never been reported in the previous studies. Identification of the genomic region and putative positional genes associated with lipid metabolism reported here should contribute to the better knowledge of the variation in IMF in Duroc pigs.

Supplementary materials The online version of this article at http://dx. doi.org/10.15302/J-FASE-2017152 contains supplementary materials (Tables S1-S2).

Acknowledgements The authors appreciate the financial support from the National Natural Science Foundation of China (31601912), the Natural Science Foundation of Guangdong Province (2016A030310447), and the Applied Science and Technology Research and Development of Special Funds of Guangdong Province (2015B020231010).

Compliance with ethics guidelines Xingwang Wang, Rongrong Ding, Jianping Quan, Linxue Yang, Ming Yang, Enqin Zheng, Dewu Liu, Gengyuan Cai, Zhenfang Wu, and Jie Yang declare that they have no conflict of interest or financial conflicts to disclose.

All applicable institutional and national guidelines for the care and use of animals were followed.

\section{References}

1. Park G B, Moon S S, Ko Y D, Ha J K, Lee J G, Chang H H, Joo S T. Influence of slaughter weight and sex on yield and quality grades of
Hanwoo (Korean native cattle) carcasses. Journal of Animal Science, 2002, 80(1): 129-136

2. Bosi P, Russo V. The production of the heavy pig for high quality processed products. Italian Journal of Animal Science, 2004, 3(4): 309-321

3. Cabling M M, Kang H S, Lopez B M, Jang M, Kim H S, Nam K C, Choi J G, Seo K S. Estimation of genetic associations between production and meat quality traits in Duroc pigs. Asian-Australasian Journal of Animal Sciences, 2015, 28(8): 1061-1065

4. Ntawubizi M, Colman E, Janssens S, Raes K, Buys N, De Smet S. Genetic parameters for intramuscular fatty acid composition and metabolism in pigs. Journal of Animal Science, 2010, 88(4): 12861294

5. Bolormaa S, Neto L R, Zhang Y D, Bunch R J, Harrison B E, Goddard M E, Barendse W. A genome-wide association study of meat and carcass traits in Australian cattle. Journal of Animal Science, 2011, 89(8): 2297-2309

6. Moloney A P, Mooney M T, Kerry J P, Stanton C, O'Kiely P. Colour of fat, and colour, fatty acid composition and sensory characteristics of muscle from heifers offered alternative forages to grass silage in a finishing ration. Meat Science, 2013, 95(3): 608615

7. Pietro Lo Fiego D, Macchioni P, Minelli G, Santoro P. Lipid composition of covering and intramuscular fat in pigs at different slaughter age. Italian Journal of Animal Science, 2010, 9(2): e39

8. Casellas J, Vidal O, Pena R N, Gallardo D, Manunza A, Quintanilla R, Amills M. Genetics of serum and muscle lipids in pigs. Animal Genetics, 2013, 44(6): 609-619

9. Muñoz M, Rodríguez M C, Alves E, Folch J M, Ibañez-Escriche N, Silió L, Fernández A I. Genome-wide analysis of porcine backfat and intramuscular fat fatty acid composition using high-density genotyping and expression data. BMC Genomics, 2013, 14(1): 845

10. Edwards D B, Ernst C W, Raney N E, Doumit M E, Hoge M D, Bates R O. Quantitative trait locus mapping in an F2 Duroc $\times$ Pietrain resource population: II. Carcass and meat quality traits. Journal of Animal Science, 2008, 86(2): 254-266

11. Cristina Ó, Oliver A, Noguera J, Clop A, Barragán C, Varona L, Rodríguez C, Toro M, Sánchez A, Pérez-Enciso M, Silió L. Test for positional candidate genes for body composition on pig chromosome 6. Genetics, Selection, Evolution., 2002, 34(4): 465-479

12. Grindflek E, Szyda J, Liu Z, Lien S. Detection of quantitative trait loci for meat quality in a commercial slaughter pig cross. Mammalian Genome, 2001, 12(4): 299-304

13. Aslan O, Hamill R M, Davey G, McBryan J, Mullen A M, Gispert $\mathrm{M}$, Sweeney $\mathrm{T}$. Variation in the $I G F_{2}$ gene promoter region is associated with intramuscular fat content in porcine skeletal muscle. Molecular Biology Reports, 2012, 39(4): 4101-4110

14. Ramos A M, Crooijmans R P, Affara N A, Amaral A J, Archibald A L, Beever J E, Bendixen C, Churcher C, Clark R, Dehais P, Hansen M S, Hedegaard J, Hu Z L, Kerstens H H, Law A S, Megens H J, Milan D, Nonneman D J, Rohrer G A, Rothschild M F, Smith T P, Schnabel R D, Van Tassell C P, Taylor J F, Wiedmann R T, Schook L B, Groenen M A. Design of a high density SNP genotyping assay in the pig using SNPs identified and characterized by next generation sequencing technology. PLoS One, 2009, 4(8): e6524 
15. Purcell S, Neale B, Todd-Brown K, Thomas L, Ferreira M A, Bender D, Maller J, Sklar P, de Bakker P I, Daly M J, Sham P C. PLINK: a tool set for whole-genome association and populationbased linkage analyses. American Journal of Human Genetics, 2007, 81(3): 559-575

16. Yu J, Pressoir G, Briggs W H, Vroh Bi I, Yamasaki M, Doebley J F, McMullen M D, Gaut B S, Nielsen D M, Holland J B, Kresovich S, Buckler E S. A unified mixed-model method for association mapping that accounts for multiple levels of relatedness. Nature Genetics, 2006, 38(2): 203-208

17. Aulchenko Y S, Ripke S, Isaacs A, van Duijn C M. GenABEL: an R library for genome-wide association analysis. Bioinformatics, 2007, 23(10): 1294-1296

18. Yang Q, Cui J, Chazaro I, Cupples L A, Demissie S. Power and type I error rate of false discovery rate approaches in genome-wide association studies. BMC Genetics, 2005, 6(Suppl. 1): S134

19. Xiong X, Liu X, Zhou L, Yang J, Yang B, Ma H, Xie X, Huang Y, Fang S, Xiao S, Ren J, Chen C, Ma J, Huang L. Genome-wide association analysis reveals genetic loci and candidate genes for meat quality traits in Chinese Laiwu pigs. Mammalian Genome, 2015, 26(3-4): 181-190

20. Burton P R, Clayton D G, Cardon L R, Craddock N, Deloukas P, Duncanson A, Kwiatkowski D P, McCarthy M I, Ouwehand W H, Samani N J, Todd J A, Donnelly P, Barrett J C, Burton P R, Davison D, Donnelly P, Easton D, Evans D, Leung H T, Marchini J L, Morris A P, Spencer C C A, Tobin M D, Cardon L R, Clayton D G, Attwood A P, Boorman J P, Cant B, Everson U, Hussey J M, Jolley J D, Knight A S, Koch K, Meech E, Nutland S, Prowse C V, Stevens H E, Taylor N C, Walters G R, Walker N M, Watkins N A, Winzer T, Todd J A, Ouwehand W H, Jones R W, McArdle W L, Ring S M, Strachan D P, Pembrey M, Breen G, St Clair D, Caesar S, GordonSmith K, Jones L, Fraser C, Green E K, Grozeva D, Hamshere M L, Holmans P A, Jones I R, Kirov G, Moskvina V, Nikolov I, O’Donovan M C, Owen M J, Craddock N, Collier D A, Elkin A, Farmer A, Williamson R, McGuffin P, Young A H, Ferrier I N, Ball S G, Balmforth A J, Barrett J H, Bishop D T, Iles M M, Maqbool A, Yuldasheva N, Hall A S, Braund P S, Burton P R, Dixon R J, Mangino M, Stevens S, Tobin M D, Thompson J R, Samani N J, Bredin F, Tremelling M, Parkes M, Drummond H, Lees C W, Nimmo E R, Satsangi J, Fisher S A, Forbes A, Lewis C M, Onnie C M, Prescott N J, Sanderson J, Mathew C G, Barbour J, Mohiuddin M K, Todhunter C E, Mansfield J C, Ahmad T, Cummings F R, Jewell D P, Webster J, Brown M J, Clayton D G, Lathrop G M, Connell J, Dominiczak A, Samani N J, Marcano C A B, Burke B, Dobson R, Gungadoo J, Lee K L, Munroe P B, Newhouse S J, Onipinla A, Wallace C, Xue M, Caulfield M, Farrall M, Barton A, and Genomics (BRAGGS) T B R A G, Bruce I N, Donovan H, Eyre S, Gilbert P D, Hider S L, Hinks A M, John S L, Potter C, Silman A J, Symmons D P M, Thomson W, Worthington J, Clayton D G, Dunger D B, Nutland S, Stevens H E, Walker N M, Widmer B, Todd J A, Frayling T M, Freathy R M, Lango H, Perry J R B, Shields B M, Weedon M N, Hattersley A T, Hitman G A, Walker M, Elliott K S, Groves C J, Lindgren C M, Rayner N W, Timpson N J, Zeggini E, McCarthy M I, Newport M, Sirugo G, Lyons E, Vannberg F, Hill A V S, Bradbury L A, Farrar C, Pointon J J, Wordsworth P, Brown M A, Franklyn J A, Heward J M, Simmonds M J, Gough S C L, Seal S,
Susceptibility Collaboration (UK) B C, Stratton M R, Rahman N, Ban M, Goris A, Sawcer S J, Compston A, Conway D, Jallow M, Newport M, Sirugo G, Rockett K A, Kwiatkowski D P, Bumpstead S J, Chaney A, Downes K, Ghori M J R, Gwilliam R, Hunt S E, Inouye M, Keniry A, King E, McGinnis R, Potter S, Ravindrarajah R, Whittaker P, Widden C, Withers D, Deloukas P, Leung H T, Nutland S, Stevens H E, Walker N M, Todd J A, Easton D, Clayton D G, Burton P R, Tobin M D, Barrett J C, Evans D, Morris A P, Cardon L R, Cardin N J, Davison D, Ferreira T, Pereira-Gale J, Hallgrimsdóttir I B, Howie B N, Marchini J L, Spencer C C A, Su Z, Teo Y Y, Vukcevic D, Donnelly P, Bentley D, Brown M A, Cardon L R, Caulfield M, Clayton D G, Compston A, Craddock N, Deloukas P, Donnelly P, Farrall M, Gough S C L, Hall A S, Hattersley A T, Hill A V S, Kwiatkowski D P, Mathew C G, McCarthy M I, Ouwehand W H, Parkes M, Pembrey M, Rahman N, Samani N J, Stratton M R, Todd J A, Worthington J. Genome-wide association study of 14,000 cases of seven common diseases and 3,000 shared controls. Nature, 2007, 447(7145): 661-678

21. Hu Z L, Park C A, Wu X L, Reecy J M. Animal QTLdb: an improved database tool for livestock animal QTL/association data dissemination in the post-genome era. Nucleic Acids Research, 2013, 41(D1): D871-D879

22. Shapiro S S, Wilk M B. An analysis of variance test for normality (complete samples). Biometrika, 1965, 52(3/4): 591-611

23. Duthie C, Simm G, Doeschl-Wilson A, Kalm E, Knap P W, Roehe R. Quantitative trait loci for chemical body composition traits in pigs and their positional associations with body tissues, growth and feed intake. Animal Genetics, 2008, 39(2): 130-140

24. Putilina T, Wong P, Gentleman S. The DHHC domain: a new highly conserved cysteine-rich motif. Molecular and Cellular Biochemistry, 1999, 195(1): 219-226

25. Ren W, Sun Y, Du K. DHHC17 palmitoylates ClipR-59 and modulates ClipR-59 association with the plasma membrane. Molecular and Cellular Biology, 2013, 33(21): 4255-4265

26. Ren W, Jhala U S, Du K. Proteomic analysis of protein palmitoylation in adipocytes. Adipocyte, 2013, 2(1): 17-27

27. Abdel-Ghany M, Sharp G W, Straub S G. Glucose stimulation of protein acylation in the pancreatic $\beta$-cell. Life Sciences, 2010, 87(2326): 667-671

28. Pandey N R, Zhou X, Qin Z, Zaman T, Gomez-Smith M, Keyhanian K, Anisman H, Brunel J M, Stewart A F, Chen H H. The LIM domain only 4 protein is a metabolic responsive inhibitor of protein tyrosine phosphatase $1 \mathrm{~B}$ that controls hypothalamic leptin signaling. Journal of Neuroscience, 2013, 33(31): 12647-12655

29. Berchtold L A, Storling Z M, Ortis F, Lage K, Bang-Berthelsen C, Bergholdt R, Hald J, Brorsson C A, Eizirik D L, Pociot F, Brunak S, Storling J. Huntingtin-interacting protein 14 is a type 1 diabetes candidate protein regulating insulin secretion and $\beta$. Proceedings of the National Academy of Sciences of the United States of America, 2011, 108(37): E681-E688

30. Matakatsu H, Blair S S. The DHHC palmitoyltransferase approximated regulates Fat signaling and Dachs localization and activity. Current Biology, 2008, 18(18): 1390-1395

31. D'Errico I, Gadaleta G, Saccone C. Pseudogenes in metazoa: origin and features. Briefings in Functional Genomics \& Proteomics, 2004, 3(2): 157-167 
32. Tam O H, Aravin A A, Stein P, Girard A, Murchison E P, Cheloufi S, Hodges E, Anger M, Sachidanandam R, Schultz R M, Hannon G J. Pseudogene-derived small interfering RNAs regulate gene expression in mouse oocytes. Nature, 2008, 453(7194): 534-538

33. Pink R C, Wicks K, Caley D P, Punch E K, Jacobs L, Francisco Carter D R. Pseudogenes: pseudo-functional or key regulators in health and disease? RNA, 2011, 17(5): 792-798

34. Watanabe T, Cheng E C, Zhong M, Lin H. Retrotransposons and pseudogenes regulate mRNAs and lncRNAs via the piRNA pathway in the germline. Genome Research, 2015, 25(3): 368380

35. Yoshida K, Yoshitomo-Nakagawa K, Seki N, Sasaki M, Sugano S. Cloning, expression analysis, and chromosomal localization of $\mathrm{BH}-$ protocadherin (PCDH7), a novel member of the cadherin superfamily. Genomics, 1998, 49(3): 458-461

36. Liu R, Sun Y, Zhao G, Wang F, Wu D, Zheng M, Chen J, Zhang L, $\mathrm{Hu} \mathrm{Y}$, Wen J. Genome-wide association study identifies Loci and candidate genes for body composition and meat quality traits in
Beijing-You chickens. PLoS One, 2013, 8(4): e61172

37. Zhang Y, Guo J, Gao Y, Niu S, Yang C, Bai C, Yu X, Zhao Z. Genome-wide methylation changes are associated with muscle fiber density and drip loss in male three-yellow chickens. Molecular Biology Reports, 2014, 41(5): 3509-3516

38. Zhou G, Wang S, Wang Z, Zhu X, Shu G, Liao W, Yu K, Gao P, Xi Q, Wang X, Zhang Y, Yuan L, Jiang Q. Global comparison of gene expression profiles between intramuscular and subcutaneous adipocytes of neonatal landrace pig using microarray. Meat Science, 2010, 86(2): 440-450

39. Mariman E C, Bouwman F G, Aller E E, van Baak M A, Wang P. High frequency of rare variants with a moderate-to-high predicted biological effect in protocadherin genes of extremely obese. Genes \& Nutrition, 2014, 9(3): 399

40. Su H, Marcheva B, Meng S, Liang F A, Kohsaka A, Kobayashi Y, $\mathrm{Xu}$ A W, Bass J, Wang X. Gamma-protocadherins regulate the functional integrity of hypothalamic feeding circuitry in mice. Developmental Biology, 2010, 339(1): 38-50 